\title{
Research on the Angle of Flaring Angle of One Way Valve
}

\author{
Yang Wang ${ }^{1, a^{*}}$ and Dongfang $\mathrm{Hu}^{2, \mathrm{~b}}$ \\ 1 Henan University of Science and Technology, School of Mechanical and Electrical Engineering, \\ Luoyang, Henan, CHINA \\ 2 Henan University of Science and Technology, School of Mechanical and Electrical Engineering, \\ Luoyang, Henan, CHINA \\ awy102344@gmail.com, bhdf@haust.edu.cn
}

Keywords: Airborne pod; One-way valve; Shaft; Flaring; Angle of extension

\begin{abstract}
The one-way valve of a certain type of airborne pod is discussed in detail; especially a lot of people are concerned about expanding process of shaft. It can not only provide the basis for the optimization design and manufacture of the product, at the same time it also can improve the structure process of this type of airborne pod. The processing mode of the original shaft end is flared when the crack is apt to appear. Therefore, the research on machining angle is very necessary. Firstly, a great deal of aspects of personnel injury sampling one-way valve shaft, and then do some tests on these samples. When determining the material properties of them, the limit expansion angles of shaft were decided by these data, and they can influence the decision process factors. In order to realize the optimization of the one-way valve shaft hole, the researchers provide the basis for determining the optimal structure of the fixtures.
\end{abstract}

\section{Introduction}

One way one-way valve is a component of air pod control system. Its main function is to control the air flow direction of airframe during flight. In the experimental center, a large amount of data is collected, and 10 sets of one-way valve assemblies are selected to study[1]. The overall damage and running time of the failure of the 10 sets of one-way valve assemblies are shown in Table 1.

Table 1 Failure check sheet for one way valve of pod ring control system

\begin{tabular}{|c|c|c|c|}
\hline Number & Date of manufacture & Operate time & Damage level $(\leq 10)$ \\
\hline 1 & 2005 & $246.81[\mathrm{~h}]$ & 8 \\
\hline 2 & 2005 & $267.09[\mathrm{~h}]$ & 8 \\
\hline 3 & 2006 & $297.74[\mathrm{~h}]$ & 6 \\
\hline 4 & 2006 & $286.66[\mathrm{~h}]$ & 6 \\
\hline 5 & 2007 & $237.65[\mathrm{~h}]$ & 6 \\
\hline 6 & 2007 & $298.04[\mathrm{~h}]$ & 7 \\
\hline 7 & 2008 & $269.02[\mathrm{~h}]$ & 7 \\
\hline 8 & 2008 & $299.43[\mathrm{~h}]$ & 8 \\
\hline 9 & 2009 & $301.44[\mathrm{~h}]$ & 8 \\
\hline 10 & 2009 & $298.21[\mathrm{~h}]$ & \\
\hline
\end{tabular}

Generally speaking, 6 stage damage refers to the components in the component still maintain the original assembly relationship, each component is complete; 7 stage damage refers to the heavy damage of parts, in which some parts are missing and the original assembly relation is not maintained; 8 stage damage means that the components only remain the valve housing and screws, but the valve plate, spring and shaft, etc., all have fallen off[2,3].

As shown in Table 1, judging from the length of the finished product, the length of the operation is basically proportional to the damage level. However, it should be noted that in 2005 and 2009, although the failure level was 8 , the running time was significantly increased. There are two reasons: First, after 
2007, the material and processing technology of the valve plate have been improved. Second, the quality of the one-way valve has been improved in order to be used widely[4].

It should be pointed out that the products at the same age, such as two pieces of failure in 2006, the running time looks bad 11.08h, and in 2007 the two failure pieces, its running time was a difference of $60.39 \mathrm{~h}$, the same data in 2008 as high as $30.41 \mathrm{~h}$. Refer to the relevant failure records found, although the process improvement of the valve plate to make failure is greatly reduced, the connecting shaft end of the flaring often cracks, the main reason is that workers only use manual direct expansion for a long time[5]. Though the method can save time and effort, it may be affected by people, resulting in product reliability problems. In view of the problem, the relation between the mechanical properties of the material and the angle of extension is effectively revealed, and an optimal process satisfying this condition is given[6].

Referring to the relevant literature, the existing literature has not yet discussed the angle of the one-way valve in the airborne pod ring control system, especially the angle of the one-way valve. This article is based on this discussion.

\section{Analysis of Problems in Processing}

One-way valve products are one of the key components in the airborne pod ring control system. The final process before the end of the assembly is to expand the shaft ends. Obviously, The purpose of the expansion is to prevent the shaft falling off the one-way valve during the operation, thus affecting the normal operation of the one-way valve.

Unfortunately, in the actual production process, technical workers in order to ensure the duration of work smoothly, have to use a hammer and expansion cone manual operation, although time-saving and labor-saving, but the shaft end flaring is prone to cracks. Sometimes, such cracks occur even in an imperceptible position, causing the failure of the one-way valve to be a sure result, and a major casualty occurs in severe cases.

If the end of the one-way valve shaft cracks, the life of the one-way valve will be greatly weakened. Once installed on the airborne pod, this kind of product can easily cause the valve plate to become loose or even fall off. In this case, the pipeline can not flow in one direction; even the missing parts are stuck inside an aircraft system and then affect the normal operation of the whole system.

\section{Mechanical Reliability and Technical Aspects of One-way valves}

Reliability Brief. Generally, mechanical reliability can be divided into structural reliability and mechanism reliability. The structural reliability mainly considers the strength of the mechanical structure and the fatigue, wear and tear caused by the impact of the load. The reliability of mechanism mainly considers the faults caused by kinematics in the course of mechanism movement.

The research object of this paper is a one-way valve for the air control system of a certain type of airborne pod. The product is the key one that affects the tightness of the air control system. The main function is to prevent air return from the system line .According to the literature of reliability research of mechanical products; the research emphasis should be mainly on the reliability of the mechanism for such one-way valves. That is to say, the emphasis analysis should be placed on a series of key components, such as shafts, springs, valves, struts and so on.

The composition, structure and working principle of the product. The one-way valve is mainly composed of a shell, a valve plate, a shaft, a bracket and a spring. The product structure is shown in Fig. 1 . 


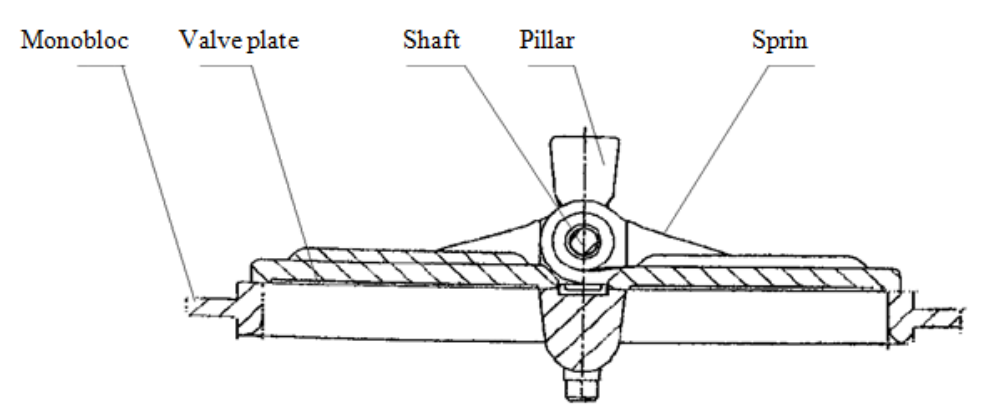

Fig.1 The structural drawing of a one-way valve model

This product has two main purposes: installed in the airborne equipment related airway key parts, to ensure the correct operation of the system; prevent air return from the system line, especially the emergency shutdown lock when the operation is abnormal.

Working principle: When the pressure difference between the two sides of the valve plate is greater than a certain value, the valve opens and the air flow passes; When the pressure difference between the two sides of the valve plate is less than a certain value or when the reverse airflow passes, the valve plate closes under the action of the return force to prevent the gas from flowing backwards.

The technical features of the one-way valve are as follows:

- The forward airflow passes and the reverse airflow is cut off;

- The product adopts the limit structure in structure, so as to improve the product life;

- The product selects the material with good corrosion resistance for surface treatment, and has strong environmental adaptability;

- The product has long service life and high reliability.

Some key technical indexes.

- Working medium: air.

- Maximum working pressure: $45 \mathrm{kPa}$.

- Maximum operating temperature: $50^{\circ} \mathrm{C}$.

- Maximum flow: (1800 \pm 50$) \mathrm{L} / \mathrm{min}$.

- Inlet pressure: $30 \mathrm{kPa}$, the temperature is $(20 \pm 10)^{\circ} \mathrm{C}$.

- Inlet flow: $900 \mathrm{~kg} / \mathrm{h}$.

- Valve flow resistance: less than $3.0 \mathrm{kPa}$.

- The reverse loading pressure value: $30 \mathrm{kPa}$, temperature $(20 \pm 10)^{\circ} \mathrm{C}$, valve leakage is less than $10 \mathrm{~L} / \mathrm{min}$.

-Maximum reverse pressure value: $60 \mathrm{kPa}$.

\section{The Importance of Machining the Shaft of a One-way Valve}

The shaft is an important part of the whole product. Its function is to fix the valve plate and spring on the valve seat so that the valve plate can be opened and closed flexibly under the influence of certain forces. Once the shaft has fallen off, the entire product will be instantly broken down. As a result, the expansion of the shaft is particularly important. The quality of the end of the shaft will directly determine the final quality of the whole product.

In production practice, if the expansion deformation of the shaft end is too small, the shaft is easy to prolapse, which directly affects the life of the whole product. And if the expansion deformation of the shaft end is too large, dilatation breach will occur easily on the shaft end. The details are shown in Fig. 2 . 


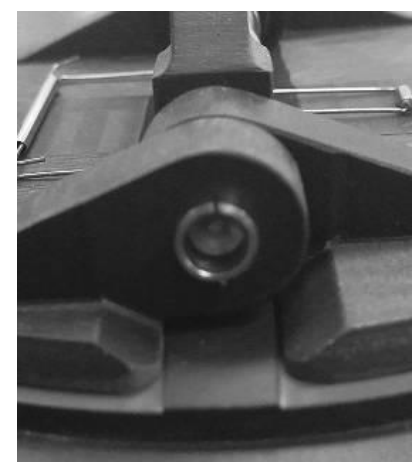

(a) When the expansion of the workpiece is too small, the shaft will be drawn out of the cross-rod.

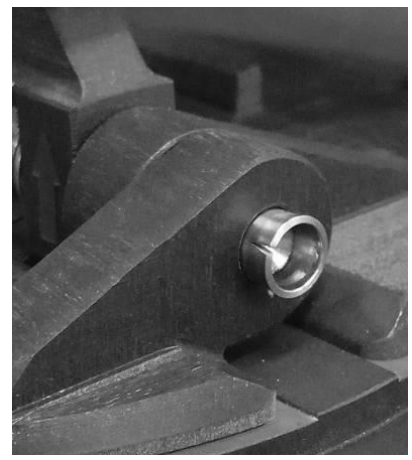

(b) When the expansion of the workpiece is too large, the end of the shaft will be damaged

Fig.2 Defective shaft opening of one-way valve

\section{Brief Description of Original Shaft Flaring Process}

There is not a very uniform standard for Installation procedure, the final original processing of the one-way valve. This resulted in the problem that many one-way valve designers could only check the national standards to select the appropriate material of the shaft for the assembly.

However, in the actual assembly process, the operators, especially those who have many years of experience worker, based solely on personal experience use the hammer head and expansion cone directly to expand the shaft end. Although the work efficiency is greatly improved, the shaft has broken inside actually, because the force is too large. As shown in Fig. 3.

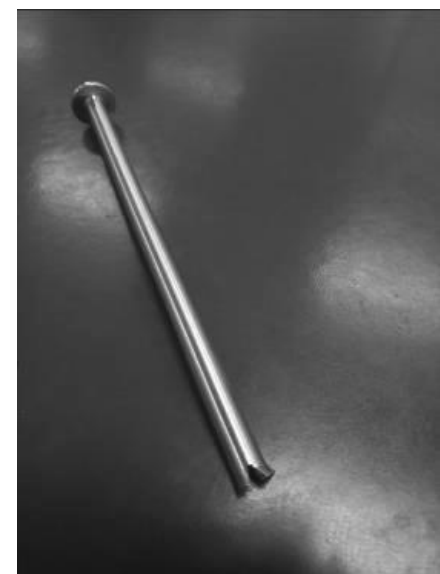

(a) Failure parts attributed to extended aperture

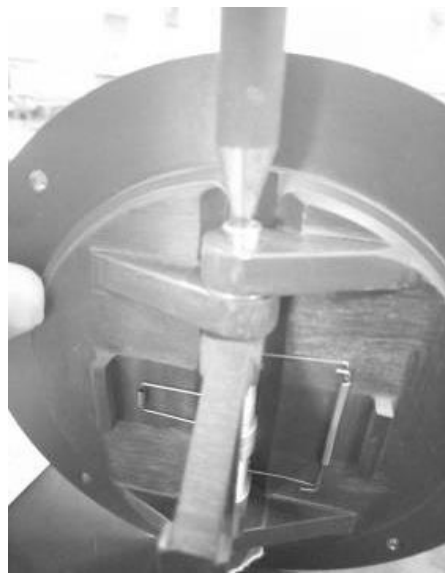

(b) Manual operation sketch map

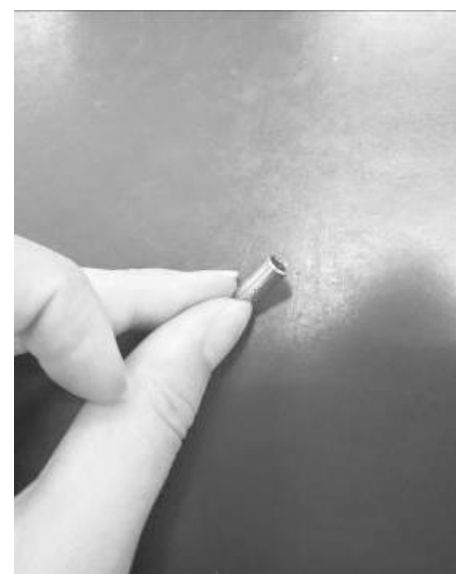

(c) The part of the fracture axis

Fig.3 The related problems in the original shaft flaring process

These situations occurred repeatedly, making the reliability of processing significantly reduced greatly. At the same time, it is becoming more and more difficult to meet the assembly requirements nowadays because of the manual operation. Therefore, is it possible to determine a criterion that is not subject to human experience between the material properties of the shaft and the expansion cone? Then, it is necessary to make a detailed analysis of the mechanical characteristics of the shaft. 


\section{Mechanical Properties of One-Way Valve Shafts}

An overview of $1 \mathrm{Cr} 17 \mathrm{Ni} 2$ materials for shafts. $1 \mathrm{Cr} 17 \mathrm{Ni} 2$ steel belongs to martensitic ferritic stainless steel. It is used for mechanical products below $400{ }^{\circ} \mathrm{C}$ after quench hardening and tempering. In addition to its good corrosion resistance and high mechanical properties, this kind of steel performs well in polishing properties, machinability and cold stamping formability.

In addition, the stainless steel can be welded in various ways. After welding, the stainless steel must be tempered at high temperature or thermal refined. However, because of the complexity of the hot working process, the slight fluctuation of the chemical composition affects the microstructure and properties of the steel, and the temper brittleness changes greatly with the temperature. It should be pointed out that in the aviation industry; the material is generally used to make load-bearing components that work in moist medium. The object of this study is the shaft products made of this material, and the main components of one-way valves are installed in the intake system of the airborne pod ring control system. The one-way valve has better moisture resistance, and can effectively realize the function of reverse airflow cut-off.

Influence of hardness of $1 \mathrm{Cr} 17 \mathrm{Ni} 2$ on shaft Reaming. In order to verify the influence of the hardness of $1 \mathrm{Cr} 17 \mathrm{Ni} 2$ on the quality of shaft flaring, 16 shafts of $1 \mathrm{Cr} 17 \mathrm{Ni} 2$ material were selected for testing, and numbered 01 to 16.

On the basis of the YB675-73 aeronautical technical indicators, the heat treatment conditions are obtained as shown in Table 2.

Table 2 specification for $1 \mathrm{Cr} 17 \mathrm{Ni} 2$ heat treatment process shown in YB675-73

\begin{tabular}{|c|c|c|c|c|c|}
\hline \multirow{2}{*}{$\begin{array}{l}\text { Technical } \\
\text { document } \\
\text { number }\end{array}$} & \multicolumn{2}{|c|}{ Heat treatment scheme } & \multirow{2}{*}{$\begin{array}{c}\sigma b \\
{[\mathrm{MPa}]}\end{array}$} & \multirow{2}{*}{$\begin{array}{c}\sigma 0.2[\mathrm{M} \\
\mathrm{Pa}]\end{array}$} & \multirow{2}{*}{$\begin{array}{l}\mathrm{HB}[\mathrm{kgf} / \mathrm{m} \\
\left.\mathrm{m}^{2}\right]\end{array}$} \\
\hline & quenching & tempering & & & \\
\hline YB675-73 & $950 \sim$ & & 1080 & - & $408-345$ \\
\hline $\begin{array}{l}\text { HB5270-8 } \\
\quad 3\end{array}$ & $\begin{array}{c}1040\left[{ }^{\circ} \mathrm{C}\right] \\
\text { Oil } \\
\text { quenching } \\
970 \sim\end{array}$ & $\begin{array}{c}275 \sim 350\left[{ }^{\circ} \mathrm{C}\right] \\
\text { Air cooling }\end{array}$ & 1080 & - & $415-352$ \\
\hline YB677-71 & $\begin{array}{c}1030\left[{ }^{\circ} \mathrm{C}\right] \\
\text { Oil } \\
\text { quenching }\end{array}$ & $\begin{array}{c}275 \sim 350\left[{ }^{\circ} \mathrm{C}\right] \\
\text { Air cooling }\end{array}$ & 1080 & - & $410-343$ \\
\hline & $950 \sim$ & $\begin{array}{c}275 \sim 350\left[{ }^{\circ} \mathrm{C}\right] \\
\text { Air cooling }\end{array}$ & 1080 & - & $415-352$ \\
\hline $\begin{array}{l}\text { HB5024-7 } \\
\quad 7\end{array}$ & $\begin{array}{c}1040\left[{ }^{\circ} \mathrm{C}\right] \\
\text { Oil }\end{array}$ & $\begin{array}{c}500 \sim 540\left[{ }^{\circ} \mathrm{C}\right] \\
\text { Air cooling }\end{array}$ & 1030 & 835 & $375-321$ \\
\hline & quenching & $\begin{array}{c}670 \sim 690\left[{ }^{\circ} \mathrm{C}\right] \\
\text { Air cooling }\end{array}$ & 835 & 635 & $302-255$ \\
\hline
\end{tabular}

According to the above indicators, combined with the present situation of the actual production, using YB75-73 technology index, are respectively set four conditions of $1000^{\circ} \mathrm{C}$ quenching with $275^{\circ} \mathrm{C}$ tempering, $1000^{\circ} \mathrm{C}$ quenching with $300^{\circ} \mathrm{C}$ tempering, $1000^{\circ} \mathrm{C}$ quenching with $325^{\circ} \mathrm{C}$ tempering , and $1000{ }^{\circ} \mathrm{C}$ quenching with $350{ }^{\circ} \mathrm{C}$ tempering. 16 test pieces, 4 for each batches, respectively, correspond to the above conditions for heat treatment. The hardness is obtained and shown in Table 3 . 
Table 3 Hardness change of specimens after heat treatment

\begin{tabular}{ccccc}
\hline $\begin{array}{c}\text { Specimen } \\
\text { mark }\end{array}$ & $350\left[{ }^{\circ} \mathrm{C}\right]$ & $325\left[{ }^{\circ} \mathrm{C}\right]$ & $300\left[{ }^{\circ} \mathrm{C}\right]$ & $275\left[{ }^{\circ} \mathrm{C}\right]$ \\
\hline 01 & $37[\mathrm{HRC}]$ & $/$ & $/$ & $/$ \\
02 & $36[\mathrm{HRC}]$ & $/$ & $/$ & $/$ \\
03 & $38[\mathrm{HRC}]$ & $/$ & $/$ & $/$ \\
04 & $37[\mathrm{HRC}]$ & $/$ & $/$ & $/$ \\
05 & $/$ & $38[\mathrm{HRC}]$ & $/$ & $/$ \\
06 & $/$ & $38[\mathrm{HRC}]$ & $/$ & $/$ \\
07 & $/$ & $40[\mathrm{HRC}]$ & $/$ & $/$ \\
08 & $/$ & $/$ & $40[\mathrm{HRC}]$ & $/$ \\
09 & $/$ & $/$ & $38[\mathrm{HRC}]$ & $/$ \\
10 & $/$ & $/$ & $30[\mathrm{HRC}]$ & $41[\mathrm{HRC}]$ \\
11 & $/$ & $/$ & $/$ & $42[\mathrm{HRC}]$ \\
12 & $/$ & $/$ & $/$ & $42[\mathrm{HRC}]$ \\
13 & $/$ & $/$ & $/$ & $42[\mathrm{HRC}]$ \\
\hline
\end{tabular}

According to the test data in the table, the hardness of the 4 groups of specimens decreases gradually with the increase of the tempering temperature. The hardness index of HRC of each group is basically in line with the YB675-73 standard. The 4 groups of specimens were tested by expansion test, and the optimum range of the expansion was verified by press loading.

The 16 test pieces machined by the same machining process have been tempered at different temperatures, and then respectively enlarge the ports with 15 degrees, 20 degrees, 25 degrees and 30 degrees flared tooling.

From the test results, it is known that with the increase of tempering temperature, the hardness of the material is gradually weakened, and the angle of expansion will be wider. Conversely, as the tempering temperature decreases, the hardness of the material increases gradually, and the expansion angle becomes narrower.

In order to further explore the relationship between the hardness value of the material and the specific angle of the expansion angle, second experiments were carried out on the material under the condition of $275 \sim 350{ }^{\circ} \mathrm{C}$ tempering air cooling. With the tempering temperature of $275{ }^{\circ} \mathrm{C}$ as the initial experimental point, each test point increased by $5^{\circ} \mathrm{C}$ in succession, until the temperature increased to $350^{\circ} \mathrm{C}$ Celsius. And at each temperature, a $\Phi 6 \mathrm{~mm}$ experimental shaft is set, a total of 16 test pieces were set up.

The 16 experimental shafts were expanded and tested respectively, and the angle of test was set to $5^{\circ}$ to $45^{\circ}$. The experimental shafts are loaded successively by installing different expansion cones on the press. For example: an experimental shaft under $275^{\circ} \mathrm{C}$ tempering air cooling conditions is expanded with a specially made flaring cone. Increase the loading angle by 5 degree each time, and the maximum angle is $45^{\circ} \mathrm{C}$. The loading pressure is constant, after each load, the experimental shaft is removed to check the extension. When the failure is found, the rough maximum loading angle without failure is obtained, and the experimental results are shown in Fig. 4. 


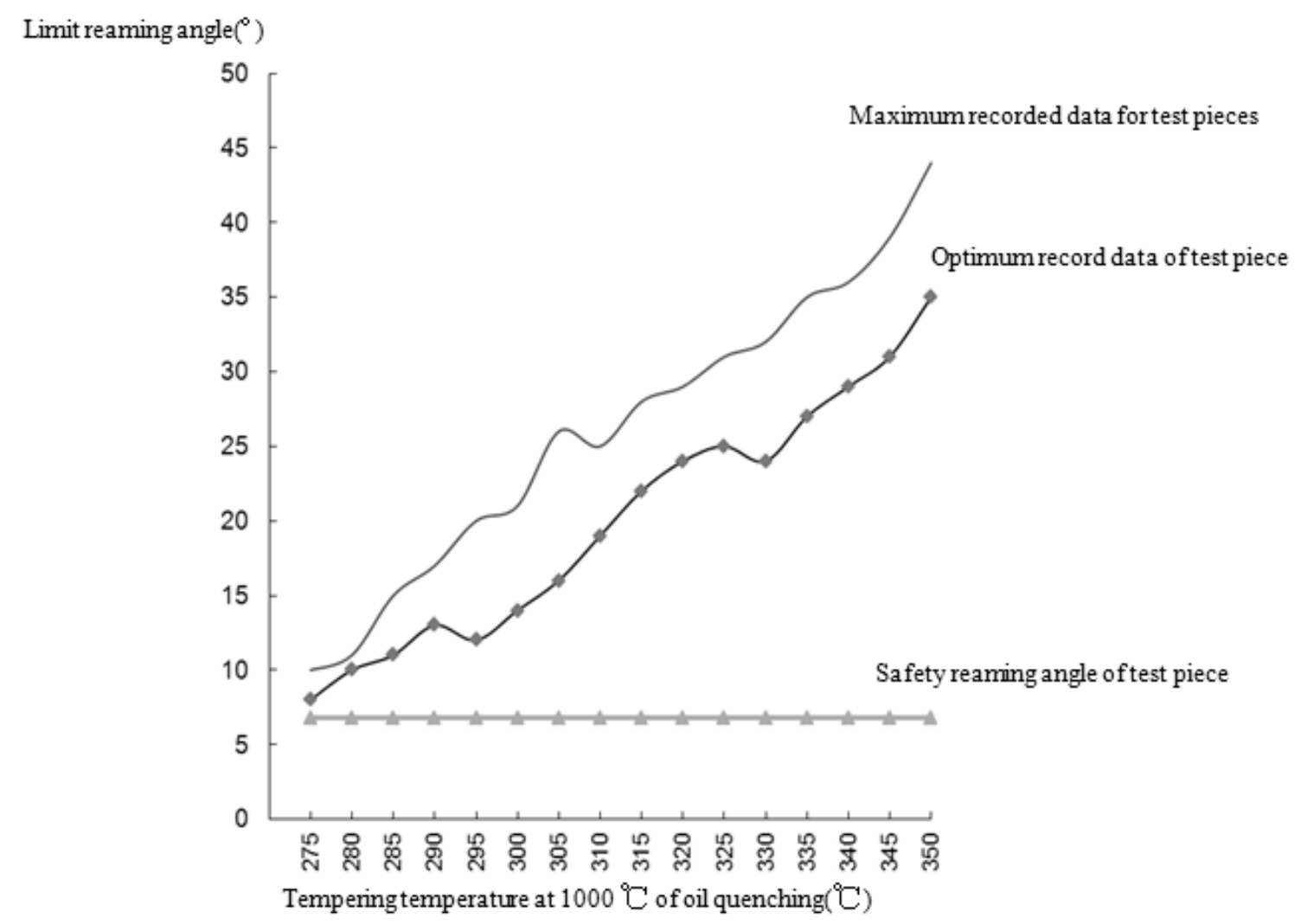

Fig.4 Influence of temperature on the angle of expansion

Through the above experiments, the approximate range of the optimum angle of expansion under different tempering temperatures was measured, which laid the foundation for the following experiments.

\section{Process Improvement and Safety Extension Angle Exploration}

The above two experiments also verify that the press is more convenient and more stable than manual expansion, and the angle of expansion can be accurately controlled by improving the process of expanding the mouth. But earlier experiments only determine the general scope, can not accurately obtain the angle of safety expansion of the press.

Typically, each type of one-way valves has been determined the shaft diameter. Therefore, when expanding with a press, there must be a lower limit angle so that the shaft does not drop out from the assembly.

In order to obtain a set of fine safety angle values, we carried out the following experiments: Taking the tempering temperature $315^{\circ} \mathrm{C}$ as an example, in the second exploration experiment, only the angle of approximate failure was determined.

We record this data as the limit angle, and then use a large number of specimens for further experiments near the data. The flaring angle with the minimum safety point weighted average, which provides a set of optimum angle of line graph, which is shown in Figure 4 in the "safe" line.

It is important to point out that the weighted average meaning is to test the angle range of the maximum flaring angle of the specimen under hundreds of specimens of the same kind (such as tempering temperature $315^{\circ} \mathrm{C}$ ).

The experimental calculations of the weighted average of the optimal angles are given below, as shown in Table 4. 
Table 4 Eighted change of expansion angle of specimen at $315\left[{ }^{\circ} \mathrm{C}\right]$

\begin{tabular}{cccc}
\hline Order $X_{i}$ & Angle subdivision range & Test number N & Weight proportion $\delta$ \\
\hline$\delta_{01}$ & $26.000\left[^{\circ}\right]-26.100\left[^{\circ}\right]$ & 6 & 0.06 \\
$\delta_{02}$ & $26.100\left[^{\circ}\right]-26.200\left[^{\circ}\right]$ & 9 & 0.09 \\
$\delta_{03}$ & $26.200\left[^{\circ}\right]-26.300\left[^{\circ}\right]$ & 8 & 0.08 \\
$\delta_{04}$ & $26.300\left[^{\circ}\right]-26.400\left[^{\circ}\right]$ & 12 & 0.12 \\
$\delta_{05}$ & $26.400\left[^{\circ}\right]-26.500\left[^{\circ}\right]$ & 13 & 0.13 \\
$\delta_{06}$ & $26.500\left[^{\circ}\right]-26.600\left[^{\circ}\right]$ & 17 & 0.17 \\
$\delta_{07}$ & $26.600\left[^{\circ}\right]-26.700\left[^{\circ}\right]$ & 14 & 0.14 \\
$\delta_{08}$ & $26.700\left[^{\circ}\right]-26.800\left[^{\circ}\right]$ & 10 & 0.10 \\
$\delta_{09}$ & $26.800\left[^{\circ}\right]-26.900\left[^{\circ}\right]$ & 5 & 0.05 \\
$\delta_{10}$ & $26.900\left[^{\circ}\right]-27.000\left[^{\circ}\right]$ & 6 & 0.06 \\
\hline
\end{tabular}

The sequence $X_{i}$ is equal in diameter and the initial value of the sequence is different from zero. $\varepsilon_{0 i}$ is the maximum recording angle for $X_{0}$, and $\gamma_{0 i}$ is the safe extension angle of $X_{i}$.

$$
\rho_{0 i}=\theta \varepsilon_{0 i}+(1-\theta) \gamma_{0 i}
$$

$\theta$ in Eq. 1 is 0.5 , and $\rho_{0 i}$ is the best record data for the $\delta$ x subdivision range. Then, the 10 sets of results are multiplied by the weight coefficient $\delta$ plus, which is the optimal record data.

There are 5 commonly used one-way valves with shaft diameters of $\varphi 2 \mathrm{~mm}, \varphi 3.5 \mathrm{~mm}, \varphi 4.5 \mathrm{~mm}$, $\varphi 6 \mathrm{~mm}, \varphi 7.5 \mathrm{~mm}$. In accordance with the technical requirements of $1040^{\circ} \mathrm{C}$ of oil quenching and $320^{\circ} \mathrm{C}$ tempering air cooling, the corresponding optimal records data are calculated, as shown in Fig. 5.

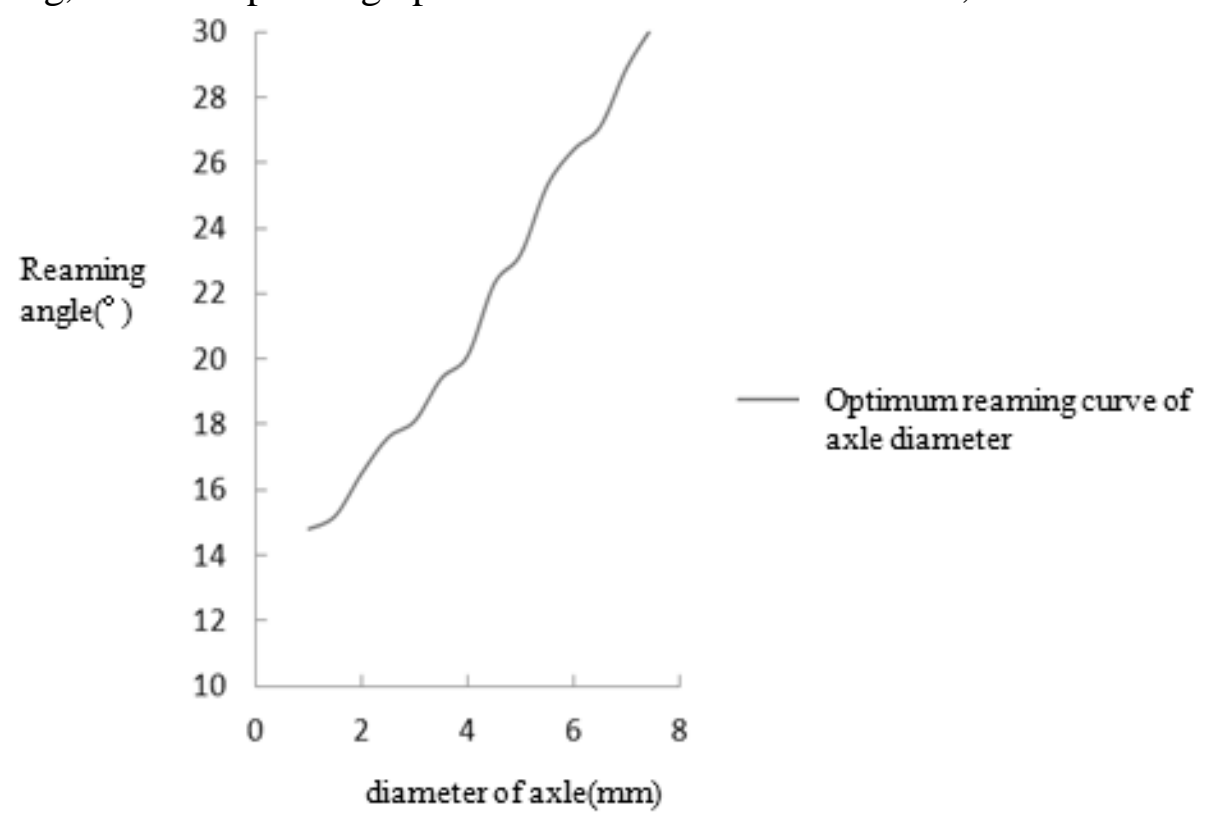

Fig.5 The optimum curve of shaft flaring under 320 degrees tempering air cooling

According to this curve, it is necessary to use the press expanding in view of the actual production process, the angle of the flaring cone is also a fixed value. Therefore, the processing angle of the $\varphi 2 \mathrm{~mm}$ axis is $15^{\circ}$, the axis of $\varphi 3.5 \mathrm{~mm}$ and $\varphi 4.5 \mathrm{~mm}$ is $20^{\circ}$, the $\varphi 6 \mathrm{~mm}$ axis is $25^{\circ}$, and the $\varphi 7.5 \mathrm{~mm}$ axis is $30^{\circ}$. Once the expansion angle is determined, the press can be used to expand the mouth. This not only simplifies the difficulty of processing, but also ensures the quality of products and assembly accuracy effectively. At the same time, other conditions can follow this method to give the corresponding characteristic curve. 


\section{Summary}

A large number of experiments have proved that the expansion of the press is more conducive to the development of the later stage of the product, and has expanded the train of thought for the assembly of similar products.

According to the safety curve of the expanding process, the designer can optimize the other type of one-way valve spindle quickly and effectively, and put forward the improvement plan. It provides a numerical basis for further research on POD structure optimization and vibration safety inspection.

In the verification of the limit angle, the relation between the angle and the hardness of the material is expounded, and the factors of the diameter of the shaft are taken into account, so that it is more suitable for the engineering practice, and has certain guiding significance for the study of this kind of process.

In the analysis of axial extension range, the discussion of adding weight after angle subdivision reduces the possibility of material performance changes due to poor heat treatment greatly, and the rate of fault tolerance is greatly improved. The scrap rate of the product shaft can be estimated through calculation, and its results are favorable to the sampling inspection by the inspectors.

\section{Acknowledgements}

The authors gratefully acknowledge the Project for education and teaching reform of Henan university of science and technology(No. 2012N-007) and the national superior course and bilingual teaching demonstration course for financial support of this research work.

\section{References}

[1] D.L. Liu, G.Y. Liu and X. Li: Failure Analysis of Non-return Valve Components, Vol. 1 (2006) No.4, p.13. (In Chinese)

[2] G.W. Liu: Forging process of punching and hole-expanding for 1Cr12Mo1V1, Vol. 33 (2008) No.1, p.14. (In Chinese)

[3] X.H. Zheng, L.L. Xie and L.Z. Liu et al,.: Characterization and Optimization of Negative Pressure Relief Valve, Vol. 25 (2014) No.22, p.3033. (In Chinese)

[4] W.N. Li, J.T. Li and H.M. Zhang et al,.: Reaserch and Generalization on Fast Adjust Method of Open-pressure about Assembled Valve, Vol. 1 (2005) No.8, p.48. (In Chinese)

[5] K. Huang, Y.T. He and P. Wei et al,.: Study on Reliability Growth Test Method for a Certain Type of Exhaust Valve, Vol. 38 (2010) No.19, p.141. (In Chinese)

[6] W.B. Liu, L. Sang: Failure Analysis on Fracture of 1Cr17Ni2 Non-return Valve, Vol. 35 (2014) No.3, p.57. (In Chinese) 